\title{
Legal Update
}

\section{The impact of cookie 'consent' on targeted adverts}

\section{Phil Lee}

is a senior associate in Field Fisher Waterhouse's Privacy and Information Law Group. His practice focuses on online privacy and digital regulation, and he has particular expertise in targeted advertising and behavioural profiling.

This article was written in August 2011. The information in this article was correct at time of writing, but neither the Journal of Database Marketing nor the author can predict with certainty further changes to the law likely to be enacted in this area by various national jurisdictions.

ABSTRACT This article explores new European legal requirements to obtain consent when serving or accessing cookies on website visitors' computers, and the impact this will have on the online targeted advertising industry. It also considers practical measures that advertisers and publishers can take to address compliance risk when serving cookies for targeted advertising purposes.

Journal of Database Marketing \& Customer Strategy Management (2011) 18, 205-209.

doi:10.1057/dbm.2011.20; published online 3 October 2011

Keywords: cookies; consent; online behavioural advertising; targeted advertising; e-privacy regulations; article 5(3)

\section{INTRODUCTION}

25 May 2011 is a date that will forever remain etched into online advertisers' minds. Why? Because it marked the official deadline for the implementation of revised e-privacy rules across the EU that require online advertisers to get users' 'consent' when serving cookies to, or accessing cookies on, users' equipment. The impact of this new 'consent' rule is enormous, and affects the entire online ecosystem - from website publishers that use cookies to operate their website, to ad networks that serve cookies for targeted advertising purposes, to the advertisers and agencies that rely on those ad networks to serve their adverts. Not least, the new rule will impact users themselves, who may now find their Web experiences impacted by intrusive requests for consent to website cookies.

\section{HOW DID WE GET HERE?}

The story started barely 2 years ago, when everyone was happy with the notice and opt-out regime for Internet cookies. At that time, Internet businesses typically made a short privacy policy disclosure telling users about cookies served through their websites and instructing users how to refuse cookies. But then, as part of a wider review of the legal framework regulating European electronic communications, the European Parliament decided to have a go at tackling the use of surreptitious means to invade Internet users' private sphere. In particular, the Parliament had the targeted advertising industry in its crosshairs, who, at that time, had been criticised for some of the lessthan-transparent practices of certain of its members. However, in their efforts to keep the law technologically neutral, the uses of cookies got scooped into the consent 
regime and by then it was too late to stop the process. The new rule lay dormant for more than 6 months until the end of 2009, when it was formally adopted, kick-starting its implementation process.

At the time, the idea of having to stop the normal flow of Internet traffic to ask for permission in order to place or access cookies seemed so out of the question that many decided to ignore it or talked themselves into thinking that nothing had changed. Indeed, many pointed to the recitals of the amended legislation, which indicated that a users' consent could be expressed through appropriate browser settings. What ensued was a heated debate about whether European legislators could have really intended businesses to obtain 'consent' in the sense that privacy professionals use it (namely, consent that is freely given, specific and informed, implying some affirmative action on the part of the individual), or whether the status quo would continue to prevail, allowing businesses to continue to rely on cookie disclosures made deep within privacy policies and assuming consent for users that did not opt out.

But then, just before summer 2010, the Article 29 Working Party, a European data protection advisory body comprising representatives from Member States' national data protection authorities, finally weighed in on the matter and expressed their view that 'consent' should mean just that - an informed indication of the individual' wishes. Put another way, the Working Party said that users must affirmatively consent to receiving cookies, before any cookies can be placed on their machines. This caused uproar among website publishers, advertising networks, agencies and advertisers alike, principally because the Working Party did not say how businesses should achieve consent, only that 'opt in' was more in line with the requirements of the Directive - leading to immediate concerns that they would have to present a flurry of pop-up windows asking for consent from every website visitor.

\section{WHAT IS HAPPENING NOW?}

European legislators face a real dilemma. Do they implement the revised e-privacy rules exactly as drafted and prolong the uncertainty or do they tweak the wording to make it more precise but risk legal action for not getting it right? Member States' governments currently seem to be struggling to find a rational way of formulating this controversial rule into their national laws, balancing the insistence of local data protection authorities that obtaining consent must not be a farce and the concerns of Internet businesses who are waiting for a silver bullet to end this surreal nightmare.

So far, only the United Kingdom and a handful of other Member States have risen to this challenge. The United Kingdom adopted the snappily titled Privacy and Electronic Communications (EC Directive) (Amendment) Regulations 2011 to implement the new 'consent' requirement, and these came into effect on 25 May, meeting Europe's implementation deadline. The result was a mixed bag, on the one hand transposing the Directive's consent obligation almost word-for-word, but, on the other, qualifying it by allowing users to express consent through browser or other application settings (in line with the Directive's recitals). Subsequent guidance published by the Information Commissioner's Office, however, made clear that reliance on default browser settings alone would not suffice to obtain consent.

In other EU countries, the situation is less forthcoming. So far, only Finland, France, Ireland and Sweden have implemented laws that appear to allow consent to be expressed through browser settings. Other territories, like Latvia and Hungary, seem to have implemented 
laws imposing strict opt-in requirements. However, in the majority of jurisdictions, the legislative silence is deafening; indeed, so much so, that the European Commission announced on 19 July its intention to pursue enforcement proceedings against Member States that fail to implement the new requirements in full (citing 20 Member States that had so far failed to do this).

As the revised e-privacy rules get slowly implemented across the EU, it seems likely that two main models will emerge - plain consent and qualified consent. Under the latter, some room for manoeuvre will be given by the law as to how that consent is obtained beyond traditional 'strict opt-in' approaches.

\section{IMPACT ON ONLINE ADVERTISING}

The impact of the rules will likely be felt most acutely by the online advertising industry, which uses cookies extensively for targeted advertising purposes. In particular, ad networks rely heavily on cookies to collect information about users' browsing behaviour and then to recognise them as they move across partnering websites in order to serve them with targeted adverts.

For example, an individual who visits the website of a popular sports brand X will have demonstrated an interest in sporting products and services. By placing a cookie through X's website onto the user's machine and assigning this a unique identifier, ad networks can record that the user with that identifier is interested in sporting products and services. When the user later moves across other partnering websites, the ad network can access his cookie identifier and look up the interests it had recorded against that identifier. It can then use this information to know that the user likes sporting products and services and tailor the adverts it serves on those websites accordingly.
Given how integral cookies are to the process of serving targeted advertising, it is hardly surprising that Europe's new cookie 'consent' requirement should cause such alarm to the online advertising industry. However, despite the tough stance taken by the Article 29 Working Party, there is some light at the end of the tunnel. As described above, the UK Information Commissioner's Office has indicated that it intends to take a pragmatic approach to enforcing the new law, and the EU Commissioner for the Digital Agenda, Neelia Kroes, steered a course between consumer protection and commercial pragmatism when, in September 2010, she said, 'We need a user-friendly solution. It would be prudent to avoid options such as recurring pop-up windows. On the other hand, it will not be sufficient to bury the necessary information deep in a website's privacy policies. We need to find a middle way'.

The problem, however, is working out what this 'middle way' should look like.

\section{RECOMMENDATIONS TO STEER A 'MIDDLE WAY'}

Ultimately, the future regulatory position of cookies and, as a consequence, targeted advertising at a European national level remains uncertain. However, bearing in mind that most territories have yet to propose how to implement the new 'consent' requirement, the existing 'notice and opt-out' regime for cookies looks likely to remain market practice in many Member States for some time yet.

Certainty will come only when the new 'consent' requirements are fully implemented across all European territories - in whatever shape and form these eventually take.

Nevertheless, aside from complying with national regulatory guidance in the few cases where this exists, there are various good practice measures that online 
advertisers can take to mitigate risk when serving cookies for targeted advertising:

\section{Identify the cookies that you serve.}

Enhancing cookie transparency is vital in building consumer trust and mitigating the risk and consequences of regulatory enforcement. However, to enhance transparency, advertisers must first identify what cookies they serve. An essential first step is therefore for advertisers to assess the number, identity, purpose and duration of each of the cookies served. Cookies that are identified as redundant or no longer serving a necessary function should be removed to reduce risk.

2. Assess the intrusiveness of the cookies you serve. The United Kingdom's Information Commissioner's Office has emphasised the importance of online service providers assessing the level of intrusiveness of each cookie that they serve. Identifying intrusiveness is a vital step in informing the level of disclosure that should be made to users about those cookies. In the context of targeted advertising, the likelihood is that users (and certainly regulators) will consider targeted advertising cookies to be more intrusive than, say, cookies to store website preferences, and these will therefore necessitate a greater level of disclosure. Intrusiveness will also be influenced by whether the cookies are first-party cookies (that is, served by the website operator itself, which users will generally expect) or third-party cookies (that is, served by a third party other than the website operator, for example an ad network, which users may not).

3. Ensure that your privacy policy clearly discloses any use of cookies for targeted advertising purposes.

As discussed above, transparency is key. As well as simply informing consumers within online privacy policies what cookies are and how they may control them, advertisers should ideally disclose each of the cookies that they use, whether they are first- or third-party cookies, whether they are session or permanent cookies, the purpose that those cookies serve (that is, targeted advertising) and their duration. To the extent possible, this should be explained in clear, simple language that users will find easy to understand - no small challenge, given the technical nature of cookies.

4. Offer 'enhanced notice' around targeted adverts displayed to consumers.

Advertisers should, wherever possible, ensure that consumers are made aware that they may be tracked for the purpose of serving targeted advertising. Recognising that consumers should be notified when they are tracked for targeted advertising purposes but that few, if any, actually read website privacy policies, the advertising industry is increasingly looking towards means of providing 'enhanced notice' to consumers about the use of targeted advertising. In the United States, the Digital Advertising Alliance has launched an 'advertising option icon' that advertisers can display around targeted adverts served to consumers, and the Internet Advertising Bureau (IAB) Europe is understood to be considering a similar approach in the EU. Consumers can click on this icon to learn more about how their information is used for targeted advertising purposes, who is using their information, what targeted advertising is, and their rights to control targeted advertising.

5. Provide a simple, easily accessible means to accept or refuse targeted advertising.

Consumers should always have an easy means by which to refuse targeted advertising, even if they had previously consented to receive it. Ideally, this would form part of the 'enhanced notice' provided to consumers alongside targeted adverts, but other common practices include the provision of 'opt-out' buttons on ad networks' websites and within publishers' privacy policies, as well as hypertext links through to sites that allow 
a 'global opt-out' across all participating ad networks offered by the IAB and the US Network Advertising Initiative.

Better still, from a legal (but perhaps not a commercial) perspective, would also be to offer consumers a means by which they can choose whether or not to accept targeted advertising in the first place. This might be, for example, through a website privacy preferences page clearly explaining the benefits and consequences of targeted advertising, and how visitors may choose to 'turn on' targeted advertising (perhaps by clicking a button or a hypertext link to indicate acceptance).

6. Apportion data privacy responsibilities within targeted advertising service contracts.

Website publishers and ad networks should apportion data protection compliance responsibilities appropriately between themselves within their targeted advertising service contracts. The Article 29 Working Party considers that publishers and ad networks both have data protection compliance responsibilities when serving targeted advertising, and therefore both may be subject to the requirements of the European Data Protection Directive. Discussing how to apportion compliance responsibilities will not only ensure that consumers' rights are properly protected, but will also help to inform publishers and ad networks about their respective compliance responsibilities - helping to avoid the risk that responsibilities 'fall between the cracks'.

7. Proactively adopt 'do not track' browser functionality.

Increasingly, the solution as to how to give individuals control over targeting technologies, while avoiding the dreaded scenario of multiple pop-up 'consent' windows, looks to lie with browser manufacturers. Microsoft, Google and Mozilla have each announced that they intend to launch 'do not track' functionality for targeted advertising in the next incarnations of their respective browsers. In addition to the recommendations described above, publishers and ad networks would therefore be well advised to proactively ensure that their website and targeting platforms will be compatible with incoming 'do not track' browser functionality. Those that do will undoubtedly better position themselves to mitigate potential risk exposure when the new cookie 'consent' regime takes full effect. 